\title{
Configurações
}

Revista de sociologia

\section{"Sacralização" do mercado de trabalho. Jovens diplomados sob o signo da precariedade}

"Sacralisation" of the labour market: Young graduates under the sign of precariousness

"Sacralisation » du marché du travail. Les diplômés sous le signe de la précarité

\section{Ana Paula Marques}

\section{OpenEdition}

\section{Journals}

\section{Edição electrónica}

URL: http://journals.openedition.org/configuracoes/183

DOI: $10.4000 /$ configuracoes. 183

ISSN: 2182-7419

\section{Editora}

Centro de Investigação em Ciências Sociais

\section{Edição impressa}

Data de publição: 30 Junho 2010

Paginação: 65-89

ISSN: 1646-5075

\section{Refêrencia eletrónica}

Ana Paula Marques, " "Sacralização" do mercado de trabalho. Jovens diplomados sob o signo da precariedade ", Configurações [Online], 7 | 2010, posto online no dia 18 fevereiro 2012, consultado o 19 abril 2019. URL : http://journals.openedition.org/configuracoes/183 ; DOI : 10.4000/ configuracoes.183

Este documento foi criado de forma automática no dia 19 Abril 2019. 


\title{
"Sacralização" do mercado de trabalho. Jovens diplomados sob o signo da precariedade
}

\author{
"Sacralisation" of the labour market: Young graduates under the sign of \\ precariousness \\ "Sacralisation » du marché du travail. Les diplômés sous le signe de la précarité
}

\section{Ana Paula Marques}

\section{Introdução}

1 Desde o seu início que a Sociologia se tem preocupado com a análise do "trabalho" e dos seus efeitos na configuração da sociedade moderna, em particular na moldagem de valores, atitudes e comportamentos dos actores sociais. A difusão das novas tecnologias de informação, bem como a aceleração da globalização da economia ${ }^{1}$ têm estado na base de uma reconversão tecnológica que se apresenta, simultaneamente, como uma reconversão ideológica. Com efeito, a "sacralização" do mercado assume -se, hoje, como ideário da justifi cação das transformações observadas ao nível dos sistemas económico, político e social, com inequívocas consequências nas relações de e no trabalho. A este propósito, a literatura sobre o "fim do trabalho", tão em voga desde os anos noventa do século XX, exprime bem os referentes dominantes que contribuem para configurar aquela ideologia neoliberal económica presente na generalidade dos países ocidentais. Na óptica de alguns autores, estar-se -á perante uma institucionalização de um regime de acumulação flexível e de uma "adequada" regulação social (Kovács, 2006a, 2006b; Santos, 2001; Beck, 2000; Giddens, 1999; Boyer \& Saillard, 1995; Boyer, 1986). Tal significa que se reivindica como condição indispensável de funcionamento daquele mercado a sua própria desregulação, instabilidade e exteriorização das condições de reprodução dos actores sociais. Ou seja, o essencial daquela argumentação tem sido no sentido de assumir a correspondência do "fim do trabalho" ao "fim do trabalho estável", fruto das exigências de flexibilidade do 
mercado de trabalho e da polivalência dos trabalhadores. Porém, na sua sustentação encontram -se premissas de partida distintas, umas mais próximas de perspectivas críticas da relação entre capital e trabalho; outras mais próximas da lógica gestionária e economicista que preconiza a auto-regulação do mercado de trabalho. Com efeito, estas questões estão dominadas, nos seus efeitos sociais, por um sentido comum ideológico de que o futuro do trabalho é obscuro e, sobretudo, incerto (se bem que para muitos possa já ter desaparecido!), pelo que se cultiva um certo "caldo de justificação" de políticas económicas, laborais, industriais, educativas, formativas, entre outras, que vão modelando não só as condições de vida como as perspectivas e as visões do mundo. Tais justificações têm um outro efeito, embora implícito, mas eficaz, de tornar desnecessária a argumentação das políticas que passam a ser "opções obrigatórias" e, por isso, inevitáveis ou indiscutíveis perante os trabalhadores, os sindicatos ou a sociedade em geral. Assim, a passagem de um "emprego para a vida" para uma "empregabilidade para a vida" suscita várias interrogações, tais como²: Qual o lugar do trabalho no mundo instável em que hoje vivemos? Que impactos sociais se poderão esperar das actuais tendências de flexibilidade, mobilidade e precariedade no emprego? O trabalho está a humanizar-se ou a desumanizar-se cada vez mais? Este contribui para gerar maiores desigualdades ou para as reduzir?

2 Antes de mais, importa referir que se assiste ao fim de uma "massifi cação" da figura do trabalhador-operário, no caso do sector económico privado, ou do estatuto de funcionário, para o sector público. Este processo teve início sobretudo a partir da crise económica do choque petrolífero, das reestruturações produtivas e da aceleração da globalização da economia. 0 enfraquecimento de certos referentes do Estado Providência, como a estabilidade de emprego e a garantia de certos direitos/concessões profissionais, é visível, por exemplo, nas actuais transformações do Código de Trabalho. A entrada em vigor da Lei n. ${ }^{\circ} 12-\mathrm{A} / 2008$ de 27 de Fevereiro tende a afectar os diversos corpos profi ssionais que trabalham sob a alçada directa do Estado e em contacto com o grande público. o fim do estatuto de "funcionário público" e a sua subjugação a um "contrato de trabalho em funções públicas" não exprime apenas uma mudança terminológica. Ela representa e enfatiza a "contratualização liberal individualista" (Santos, 1998), dominante na definição das relações de trabalho e de emprego.

3 Esta crescente individualização das relações de trabalho encontra -se, em regra, associada a novas formas de contratualização que escapam às relações "típicas" de emprego, por comparação com a norma vigente de contrato de trabalho permanente. Tal permite que se assista a uma diversidade crescente de estatutos sociais assumidos pelos diversos grupos profi ssionais, incluindo jovens diplomados (Marques, 2006, 2005, 2001). A profusão destes estatutos decorre de imperativos económico -políticos, mas também de recomposições técnico -organizacionais e, ainda, de dispositivos públicos de apoio ao emprego e formação, pelo que temos hoje uma mão-de-obra heterogénea, composta por trabalhadores "estáveis", "precários", "prestadores de serviços", “estagiários", "bolseiros", entre outros. Por sua vez, as trajectórias profissionais, além de não se apresentarem homogéneas, também não se apresentam lineares ou contínuas no tempo e no espaço. Igualmente, com as deslocalizações das empresas e as constantes mutações tecnológicas e comunicacionais, um número crescente de trabalhadores, sobretudo de baixo nível de qualificação escolar ou de idade avançada, apresenta problemas sérios de reconversão profi ssional, enfrentando, em muitas situações, o desemprego. No limite, estão em curso reconfi gurações 


$$
\text { de relações duráveis que permitam a (re)construção de colectivos de trabalho, de }
$$
"culturas de trabalho"3.

ante a vastidão e a complexidade desta temática, iremos estruturar o presente artigo com o objectivo de: $i$ ) identificar os traços normativos, sociocognitivos e simbólicos específicos da crescente individualização das relações de trabalho que caracterizam o início de carreira profissional de jovens diplomados; ii) reflectir sobre os processos de ressimbolização do trabalho que defi nem os principais contornos das relações de e no trabalho no actual regime de acumulação fl exível. Será dado particular destaque às contradições que acompanham as transformações nas relações de e no trabalho, em particular as que se prendem com as formas "subtis" de dominação nos quotidianos de trabalho (Poitet, 2007; Bourdieu, 1998; Gollac e Volkoff, 1996). Estas apresentam contornos crescentes de visibilidade na mobilização de formas diversifi cadas de contratualização laboral, na individualização e informalidade no acesso ao mercado de trabalho, na intensificação dos ritmos de trabalho acompanhada por maiores exigências de gestão das fronteiras profissionais e privadas/familiares, entre outros aspectos.

\section{Da reconversão tecnológica e ideológica}

\subsection{Importância paradoxal do trabalho}

6 Transformado nas suas formas, o trabalho evolui, igualmente, no seu conteúdo e na sua significação social (Freire, 1997; Gamst, 1995). Os argumentos desenvolvidos sobre o futuro ou o fim do trabalho assentam, pelo menos, em duas ideias interdependentes: a alegada supressão material do trabalho e a transformação dos seus significados para as pessoas. Ora, estes debates assumem que tanto o trabalho como o seu contexto evoluíram e contribuíram para aumentar a complexidade das sociedades actuais. Com efeito, as manifestações disso mesmo são visíveis não só ao nível mais tangível e explícito - como sejam as transformações na materialidade das actividades executadas nos diferentes contextos de trabalho - nos constrangimentos das Tecnologias de Informação e Comunicação (TIC) e das novas formas de organização do trabalho, tendo como base o actual contexto de globalização; mas também a um nível implícito e subtil, que se prende com as transformações nos referentes identitários, na (re)construção do lugar de cada um e de todos (Dubar, 1991, 2000; Pinto, 1991, 2001), traduzindo -se esse trabalho classificatório na actual proliferação

7 de vocábulos associados, tais como: operadores, estagiários, trabalhadores polivalentes e fl exíveis, trabalhadores do quadro ou temporários, entre outros.

8 Assim, tal como no passado, o trabalho exprime hoje profundos contrastes, sendo que a centralidade atribuída ao trabalho assume, cada vez mais, um estatuto paradoxal. Tal explica -se, por um lado, porque o trabalho abstracto (valor de troca) continua no centro da dinâmica capitalista. Por outro lado, ao tornar-se mais volátil, escasso e difícil de manter, o trabalho tende a provocar uma desfiliação ao nível das redes de sociabilidade, incluindo uma desestruturação da vida pessoal, familiar e social para muitos dos grupos sociais privados de qualifi cações profi ssionais com valor na actual lógica de mercado e, muito em especial, para os que estão privados de um emprego por um longo período (Marques, 2009).

Configurações, 7 | 2012 
9 Na verdade, quer no plano social, nas significações e valorações, quer no plano individual e subjectivo, os conhecimentos suportados pelos inquéritos sociológicos (Freire, 2001) revelam -nos que o trabalho é o segundo valor, a seguir à família, estando longe dos valores relacionados com os amigos, o lazer e a religião. Por sua vez, associa -se ao trabalho, igualmente, um modo de realização de si e de estatuto e identidade social. Já no plano subjectivo, as aborda-gens clínicas e psicopatológicas têm destacado que o trabalho desempenha um papel decisivo nas regulações psíquicas. Sabe -se que, em termos psicológicos, o trabalho se apresenta central não em si mesmo, mas enquanto possibilidade de regulação de opções e arbitragens dos investimentos individuais no seio de várias esferas de actividade (e.g., familiar, privada). Nesse mesmo sentido, vários estudos sociológicos têm -se debruçado sobre as consequências psicológicas e os riscos de dissociação social resultantes da vivência do desemprego, sobretudo de longa duração, e de rejeição da desvalorização desse estatuto (Marques, 2009, 2006; Paugam, 1997; Castel, 1991). É, ainda, de referir que, se o tempo de trabalho remunerado regride, a explosão de tempos de não subordinação directa ao trabalho não deve ocultar o que os seus estatutos e práticas sociais devem aos modos de inserção concreta na esfera produtiva (e.g., reforma, invalidez, beneficiários de subsídio de desemprego). Ou seja, mesmo na sua privação, o trabalho constitui a expressão das contradições que o atravessa, permanecendo um bem primordial que, ao lado da família e da comunidade, é decisivo para contrariar a insegurança, a desfiliação e o risco que ameaça o indivíduo, cada vez mais vulnerável e solitário, em contextos familiares em recomposição e em sociedades envelhecidas.

Por conseguinte, a pretexto de uma economia competitiva e inovadora, a lógica que parece imperar é a do mercado e do seu valor supremo e a inquestionável "sacralização do mercado" que, para alguns autores, ocupa o lugar central do sagrado de outrora (Moreno, 1999). Quando o trabalho não se integra no mercado, quer dizer, quando não funciona como mercadoria, com valor de troca, está desvalorizado socialmente ou não se percebe sequer a sua existên-cia: assim ocorre com o trabalho das "domésticas" que não trabalham, apenas fazem as suas actividades de casa, ou com o trabalho que realizamos para nós mesmos, que possui, quando muito, um grande valor de uso ${ }^{4}$. E é com esta mesma lógica que se interpreta a situação dos desempregados de longa duração (Marques, 2009), dos jovens sem emprego, dos inactivos, que são socialmente marginalizados porque estão excluídos do mercado de trabalho.

11 Portanto, o trabalho convoca vários registos que não são necessariamente equivalentes entre si, designadamente, económico, coercivo, simbólico, jurídico-normativo e identitário. Assim, é necessário ter presente a historicidade e a relatividade da noção de trabalho, considerando a sua evolução ao longo do tempo e, certamente, a sua vivência heterogénea pelos diferentes grupos sociais: homens, mulheres, jovens, trabalhadores com qualificações obsoletas, jovens em início de uma carreira, entre outros. Tal permite, mesmo hoje, percepcionar muitos dos fenómenos de injustiça social associados ao trabalho.

\subsection{Individualização e erosão de "culturas de trabalho"}

12 Um dos outros eixos analíticos privilegiados da actual reconversão ideológica do trabalho reside nas tendências de desregulação, privatização, individualização e flexibilização das relações de trabalho que contribuem para o desmantelamento do Estado Social e das 
"culturas de trabalho". A expulsão, a marginalização e a precarização de um conjunto cada vez mais diversifi cado de grupos sociais contribuem para a erosão das culturas de trabalho entendidas como espaços -tempo de uma aprendizagem colectiva, ao mesmo tempo biográfica e relacional, de aquisição de saberes e competências, de normas e modelos culturais, de valores e orientações ideológicas de identificação e, simultanea mente, de distinção de uns em relação aos outros.

Com efeito, nos processos de trabalho não estão em causa apenas a produção concreta de produtos ou serviços e a reprodução da ordem ideológica, mas também a partir deles se definem modelos de interacção, relações de poder e de hierarquias valorativas que contribuem para a definição de culturas de trabalho. Nesse sentido, incluem -se os contributos da sociologia francófona e italiana, desde a perspectiva das consequências da "cultura técnica" na natureza e conteúdo do trabalho e do destaque das representações sociais em torno das experiências concretas de trabalho. Porém, além destes contributos teóricos, será relevante inserir as culturas de trabalho numa "matriz estrutural identitária" (Moreno, 1999) que se define pela análise dos processos de trabalho no desen volvimento concreto de relações sociais de produção específicas. Tal pressupõe que, em termos teóricos -metodológicos, qualquer experiência social de trabalho não só contempla, na sua base, as condições materiais de existência dos agentes económicos (e.g., empresários, trabalhadores), as suas práticas, saberes, representações e valores, como também incorpora outras dimensões da vida social e das representações sociais que se forjam a partir dela: desde a defi nição de opções ou estratégias familiares até à forma de se representar a si e ao mundo, a vida do quotidiano e o tempo livre, entre outras dimensões.

14 Nesta linha de argumentação, as identidades produtivas, sejam elas de classes sociais, de categorias profissionais ou de profi ssões, encontram -se interdependentes de identidades de sexo -género e de identidades étnicas (ou etno-nacionais), pelo que, apenas em termos analíticos, se poderá aceitar a sua análise independente. Na verdade, não funcionando como culturas em abstracto e reificadas, os conteúdos das culturas de trabalho geram -se a partir dos elementos caracterizadores dos processos produtivos nas suas dimensões mate-riais, interactivas e simbólico -ideológicas ${ }^{5}$ - e das relações sociais de género e de etnia. Assim se poderá explicar que os processos de divisão social do trabalho sejam, simultaneamente, processos de divisão sexual, que se caracterizam pela persistência de práticas androcêntricas, pela existência de uma estrutura socioprofissional segregada e modelos culturais masculinizados (Marques, et al., 2006).

Ao valorizar-se a competitividade, a produtividade, a individualização e a flexibilidade do trabalhador, no essencial, a empregabilidade permanente (McQuaid e Lindsay, 2005; Marques, 2004, 2001; Gazier, 1990, 1998), está-se a transformar as condições sociais do exercício da actividade profi ssional, os quadros de interacção quotidiana e as orientações simbólicas. Com efeito, nesta reflexão geral sobre a reconversão ideológica baseada na ofensiva neoliberal de sacralização do mercado, as consequências - umas visíveis, outras mais implícitas - são relevantes, tais como: $i$ ) extensão do desemprego estrutural; ii) difusão de formas precárias e atípicas de emprego; iii) insucesso das políticas sociais e dos dispositivos de mediação; iv) tensão entre "emprego para a vida" e "empregabilidade para a vida"; v) substituição do termo "trabalho" pelo de "actividade", cuja latitude se torna mais ajustável na lógica de fl exibilização; e, por último, vi) segmentação a vários níveis da força de trabalho, desde os "integrados" e "precários" aos "excluídos" do mercado de trabalho. Justamente, são estes os traços que permitem defi nir as condições para que se 
assista a uma progressiva erosão de culturas de trabalho, até então dominantes, e se questionem os novos suportes de culturas de trabalho emergentes.

De forma necessariamente breve e recorrendo a informação substantiva obtida nas investigações por nós realizadas ${ }^{6}$, iremos destacar algumas das contradições que acompanham as transformações nas relações de e no trabalho, em particular as que se prendem com as formas "subtis" de dominação nos quotidianos de trabalho por parte de jovens diplomados. Estas apresentam contornos crescentes de visibilidade na mobilização de competências e de confi ança, no quadro de relações definidas pela instabilidade e vulnerabilidade da relação de trabalho e emprego, na exteriorização das condições de reprodução da mão -de-obra em contraponto com a configuração dos espaços de trabalho como espaços formativos e de aprendizagem e, ainda, na ruptura de relações duráveis que permitam a (re)construção de colectivos de trabalho, de culturas de trabalho.

\section{Jovens diplomados sob o signo da precariedade}

17 Perante a crescente incerteza, instabilidade e precariedade que caracteriza a maior parte dos percursos dos jovens que saem da universidade e acedem ao mercado de emprego, o debate sobre a "inserção profissional" tem conhecido um renovado interesse dos responsáveis pelas políticas educativas e de emprego, especialistas e investigadores, empregadores, famílias e sociedade em geral.

\subsection{A instalação na precariedade ${ }^{7}$ : modelo alternativo de inserção}

Os novos registos da actividade produtiva não se confinam mais apenas a um emprego convencional estável. 0 emprego estável regride a favor do temporário, do parcial e do precário. As pressões exercidas pelos diversos grupos sociais sobre a alteração da norma da relação de emprego convencional têm remetido o Estado para um papel de "supervisor" com uma infl exão crescente da sua intervenção legislativa e executiva.

A amplitude pressuposta na relação trabalho e emprego ajuda -nos a pensar, sobretudo, na diversidade de situações e modalidades que pode assumir, impondo uma complexidade e incerteza crescentes em torno desta relação. Referimo -nos, por exemplo, à intensificação do ritmo de trabalho não só para os que têm um emprego, mas também para todos aqueles que vivem uma relação precária de trabalho (pela flexibilização/ desregulação da relação salarial, do emprego "atípico", da polivalência desqualificante, do desemprego intermitente, dos riscos dos trabalhadores por conta própria, ou da expansão do sector informal e não declarado, que recobre situações de sobreexploração), que suportam normas de rendibilidade excessivas, com todas as consequências para a segurança e a qualidade do trabalho, para a saúde mental, para a organização da vida familiar e cívica. Com efeito, para Foucarde (1992), uma situação típica de emprego pressupõe três elementos essenciais: $i$ ) a durabilidade da relação de emprego; ii) a unicidade do empregador e a pertença a um serviço organizado; iii) e o horário a tempo inteiro com salário equivalente. Em oposição, por situações "atípicas" de emprego entendem -se todas aquelas que resultam da não verificação de um, de outro ou de todos aqueles elementos referidos. De um modo geral, estas formas atípicas de trabalho podem ir desde actividades simplesmente não declaradas ${ }^{8}$ a formas de contratos temporários, a tempo inteiro ou a tempo parcial. 
Portugal tem vindo a registar um acréscimo de formas atípicas de trabalho - na sua maioria resultantes da iniciativa das entidades empregadoras - que se traduz quer no aumento dos contratos a termo (certo e incerto), quer no crescente número de trabalhadores por conta própria (em regime de recibo verde), quer, ainda, na proporção de trabalhadores a tempo parcial. Segundo os dados disponíveis, Portugal apresentou, em 2007, uma percentagem de contratos não permanentes (de duração limitada) superior $(22,4 \%)$ à média europeia dos 25 Estados -Membros (15,1\%). Igualmente, a taxa de emprego a tempo parcial é, no total da população activa, 12,1\% (com maior incidência nas mulheres) ${ }^{9}$, sendo que a média europeia é de 18,8\% (Eurostat, 2007).

21 Desta forma, se assumirmos o vínculo contratual como o argumento central da tese até então dominante, assente na estabilidade da relação de trabalho como a primeira e importante representação da inserção profi ssional para muitos dos jovens licenciados, importa confrontá -lo com os nossos resultados, em particular os que resultam do Projecto MeIntegra (Marques, 2007), que analisou o percurso de diplomados de várias áreas científicas ${ }^{10}$.

2 Assim, é possível refutar, antes de mais, aquela tese, já que apenas 15\% dos entrevistados declararam ter, actualmente, uma relação contratual permanente. Mesmo assim, este valor é superior ao declarado no início da actividade profi ssional (6\%) (cf. Gráfi co 1).

Gráfi co 1 - Vínculo contratual no início da actividade e actualmente (\%)

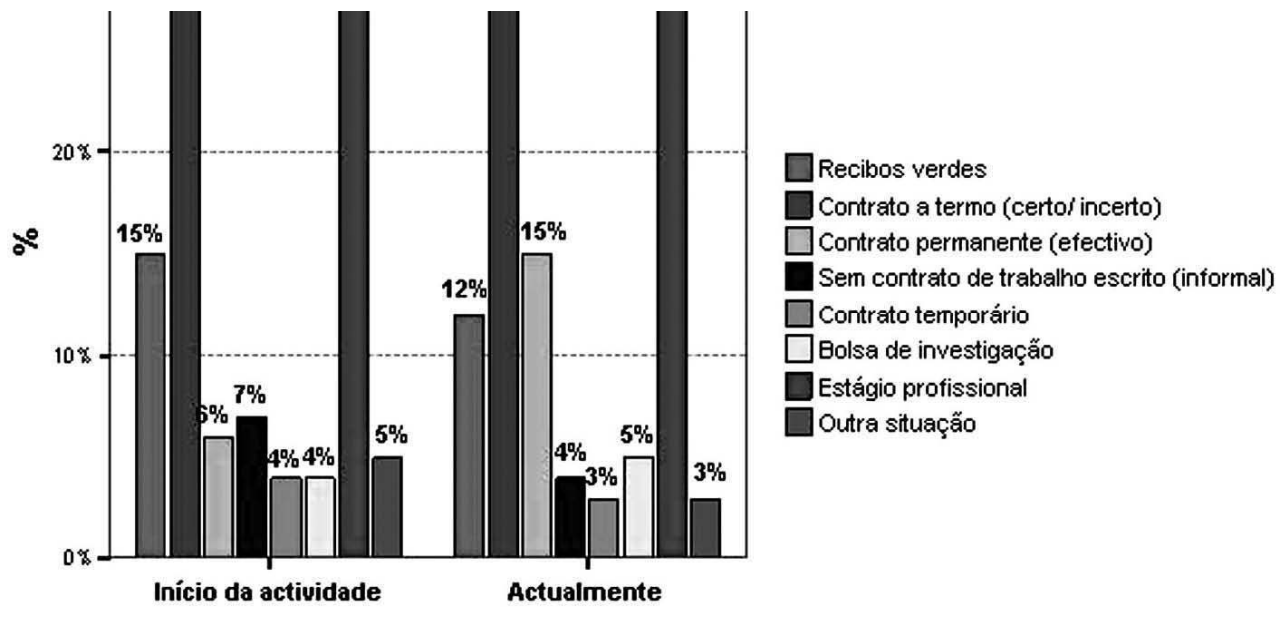

FONTE: Projecto Melntegra $(2006 / 07, \mathrm{~N}=464)$

Deste modo, ganha mais consistência a tese alternativa que tem vindo a ser avançada nos anos mais recentes. Esta caracteriza -se pelas práticas de recrutamento de jovens quadros baseadas na utilização preponderante de modalidades de estágios profissionais ou de figuras jurídicas de contrato a termo, ou, ainda, de prestação de serviços (sob a forma de recibos verdes). Tendo em conta os resultados obtidos nesta investigação, esta tese é, em grande medida, corroborada. Senão vejam -se os seguintes dados: $30 \%$ dos jovens encontram -se em estágio profi ssional; $29 \%$ com contrato a termo; e $12 \%$ a "recibos verdes".

Porém, importa ter presente que, apesar de a situação de vulnerabilidade e precariedade de emprego atingir todos os jovens licenciados ${ }^{11}$, a verdade é que, em termos relativos, as formas mais desreguladas desse vínculo de trabalho estão mais presentes nas áreas onde se registam maiores dificuldades de inserção profissional, nomeadamente nas 
"Humanidades e Ciências Sociais". Com efeito, a análise por grande área científi ca apresenta -se relevante já que permite verificar que na situação contratual de prestação de serviços (modalidade de "recibos verdes"), e na situação de não ter um contrato escrito estão, sobretudo, jovens oriundos das Humanidades e Ciências Sociais. Em sentido relativamente oposto, em situação quer de bolsa de investigação, quer de uma formalização da relação de trabalho encontram -se proporcionalmente mais jovens da fi leira de "Tecnologias e Engenharias" (cf. Quadro 1).

Quadro 1 - Vínculo laboral por grande área científi ca (\%)*

\begin{tabular}{|c|c|c|}
\hline & \multicolumn{2}{|c|}{ Área científica } \\
\hline & $\begin{array}{l}\text { Humanidades } \\
\text { e Ciências Sociais }\end{array}$ & $\begin{array}{l}\text { Tecnologias } \\
\text { e Engenharias }\end{array}$ \\
\hline Recibos verdes & 70,5 & 29,5 \\
\hline Contrato a termo (certo/incerto) & 40,7 & 59,3 \\
\hline Contrato permanente (efectivo) & 42,1 & 57,9 \\
\hline $\begin{array}{l}\text { Sem contrato de trabalho escrito } \\
\text { (informal) }\end{array}$ & 73,3 & 26,7 \\
\hline Contrato temporário & 41,7 & 58,3 \\
\hline Bolsa de investigação & 15,8 & 84,2 \\
\hline Estágio profissional & 56,6 & 43,4 \\
\hline Outra situação & 80,0 & 20,0 \\
\hline Total & 50,3 & 49,7 \\
\hline
\end{tabular}

FONTE: Projecto Melntegra $(2006 / 07, \mathrm{~N}=464)$

* $(\mathrm{v}=0,284 ; \mathrm{P}=0,000)$

Por conseguinte, um dos traços que caracterizam actualmente as práticas de recrutamento deste segmento de jovens, quadros de formação superior, consiste na inclusão progressiva de formas "atípicas" de emprego como uma modalidade generalizada de gestão dos recursos humanos (Rebelo, 2003; Célestin, 2002; Rodrigues, 1991). Assim, interessa -nos registar, desde já, a ideia central da descontinuidade previsível do vínculo laboral, no tempo e no espaço de trabalho, como um dos traços de caracterização dos percursos de inserção dos jovens licenciados.

$\mathrm{Na}$ verdade, para a explicação e a compreensão da inserção profi ssional dos jovens licenciados, importa contemplar tanto os constrangimentos de diversa ordem (e.g., classe, género, fi leira científica), como as estratégias de inserção que podem ser desencadeadas pelos actores sociais. Assim, a vivência inicial de várias experiências profissionais constitui, cada vez mais, um processo normal de inserção para os jovens que se estende por períodos de tempo alargados, descontínuos e reversíveis. Igualmente, apesar de a inserção profissional dos jovens inquiridos se apresentar globalmente positiva, são inquestionáveis as recomposições em curso nos padrões e modelos culturais, nas relações sociais ao nível do contexto familiar, escolar e profissional da geração actual (e sua relação com outras gerações). 


\subsection{Informalidade e subjectivação das relações de trabalho}

27 A crescente individualização das relações de trabalho permite, em certa medida e de forma paradoxal, uma aproximação dos sistemas educativo e produtivo que, formalizam, ainda que com contornos fluidos, a acção individual em termos de competências técnico científicas e, sobretudo, transversais. Esta aproximação não está, porém, isenta de manifestações de resistência por parte de certas instituições, em particular as do Ensino Superior (áreas disciplinares, concepções pedagógicas e fechamento corporativo), à abertura e à inovação face ao exterior (ao mundo empresarial e sua lógica).

A ênfase nas competências evidencia, sobretudo, a mobilização subjectiva de cada um nas relações de trabalho e emprego, suas modalidades e constrangimentos, e no empenho "natural" das qualidades pessoais que confi guram os actuais perfi s profissionais. Desempenha, portanto, um papel na apropriação, pelo indivíduo, da sua trajectória e da sua história, bem como na reutilização dos seus saberes (recursos) cognitivos e sociais no seu percurso futuro.

Este apelo à construção de uma posição/lugar na sociedade por cada um, ou seja, um apelo à "acção" ou à "construção do espaço de acção" (Terssac, 1998: 235 -236), permite nos realçar três aspectos deste processo: o primeiro diz respeito à identificação de todas as qualidades (e não só dos saberes formais, transmitidos e certificados pela educação e formação) que são investidas na acção e que contribuem para a sua concretização; o segundo explicita o que está na base de perfis dotados de "empregabilidade permanente" (Marques, 2001) num determinado contexto organizacional; o terceiro enfatiza a avaliação de desempenho e a trajectória profi ssional do indivíduo.

Neste contexto, hoje não se emprega um trabalhador apenas com base na sua qualificação, mas também com base num potencial de adaptação. A exigência acrescida sobre a qualidade das pessoas acentua ainda mais essa incerteza. Para os empregadores, o candidato a um emprego deve poder apresentar capacidade de adaptação e de reaç̧ão às novas situações profissionais, aos imprevistos e aos problemas que possam surgir no local de trabalho. Quer dizer, o candidato ao primeiro emprego, além de fazer prova destes "saberes -qualidade", inobserváveis a priori num jovem diplomado, deve mobilizar saberes gerais, saberes técnicos e profissionais, preferencialmente certificados por um diploma. Para os jovens quadros, em concreto, o diploma pode tornar-se num elemento de selecção ou de discriminação. Embora a posse do diploma não garanta, todavia, o acesso a um emprego, a sua falta pode ser um factor de desqualifi cação profissional e social. A pressão para a certificação dos saberes actualiza a questão do emprego, já não só restrita a grupos sociais que tradicionalmente tinham dificuldades em aceder ao mercado de trabalho, como também aos diplomados e aos já inseridos, pela força da concorrência nos empregos e da instabilidade económica.

31 Por outro lado, há situações de não visibilidade ou de não contemplação de muitas iniciativas de investimento em formação (pós -graduações, mestrados, especializações, ou mesmo doutoramentos) como investimentos produtivos. Concretamente, trata -se de situações de estagiários que não são contabilizados entre os activos ocupados ou de desempregados que retomam os estudos na universidade, ou, ainda, de adultos que acumulam o trabalho a tempo inteiro com os estudos, com acções de formação da sua iniciativa e de autoformação. Também aqui podemos pensar que este investimento pode ser visto como uma estratégia de defesa, preparação ou antecipação para as exigências do 
mercado de trabalho. Neste contexto, a teoria do capital humano constitui -se ainda como uma referência importante.

De um modo geral, a informalidade e a subjectivação das relações de trabalho, em particular no momento do recrutamento, predominam tanto na óptica dos licenciados como na dos empregadores (cf. Quadro 2). Ambos apresentam práticas próximas de uma "gestão personalizada" ou "informal", aquando da selecção e recrutamento deste segmento qualifi cado de mão -de -obra.

O peso das redes de mediação, entranhadas no próprio tecido empresarial e assentes no interconhecimento, relega para plano secundário outras estratégias mais formais e institucionais. Com efeito, comparando os meios de recrutamento mais utilizados pelos licenciados e pelas empresas, verificamos que a candidatura espontânea/envio do CV se apresenta central no processo de transição para o mercado de trabalho, em especial para o licenciado. Além disso, para as empresas, os conhecimentos pessoais apresentam, em seguida, a percentagem relativa mais importante. Também os anúncios no jornal são valorizados por estes dois grupos, embora com pesos diferentes. A empresa, sentindo necessidade de contratação, privilegia, em terceiro lugar, a colocação de um anúncio no jornal. o licenciado, por seu turno, elege a procura e resposta aos classifi ca-dos como o segundo meio mais utilizado na procura de emprego.

Quadro 2 - Meios de recrutamento na óptica dos licenciados vs empresas (\% de respostas positivas)

\begin{tabular}{|l|c|c|}
\hline & Licenciados & Empresas \\
\hline Contactos profissionais & 24,1 & 15,5 \\
\hline Candidaturas espontâneas/envio de CV & 67,7 & 46,0 \\
\hline Empresas de recrutamento e selecção & 19,8 & 7,5 \\
\hline Conhecimentos pessoais (familiares, amigos) & 21,6 & 36,6 \\
\hline UNIVA (Unidade de Inserção na Vida Activa) & 10,9 & 3,3 \\
\hline Universidade & 19,4 & 21,1 \\
\hline Centro de Emprego - IEFP & 45,7 & 20,5 \\
\hline Estágio curricular & 21,2 & 18,6 \\
\hline Estágio profissional & 26,9 & 21,9 \\
\hline Anúncios no jornal & 56,3 & 28,3 \\
\hline
\end{tabular}

Fonte: Projecto Melntegra (2006/07, N=464)

Sem rejeitar aquela tendência, acentua -se, igualmente, a recente "institucionalização" ao nível do processo de recrutamento, dada a visibilidade do Centro de Emprego (IEFP), sobretudo junto dos licenciados. Estes recorrem, mais imediatamente do que as entidades empregadores, a instituições especializadas para os ajudarem na procura de emprego. Além disso, se considerarmos a importância dos estágios curricular e profissional, bem como do papel da universidade como interlocutora no processo de transição dos licenciados para o mercado de trabalho, aquela vertente institucional surge ainda mais reforçada. Estas modalidades, caracterizadas por um enquadramento de apoio à transição, apresentam proporções relativamente idênticas para ambos os grupos -alvo. Para os jovens, estas constituem uma oportunidade efectiva de contacto com o mundo de trabalho e de aperfeiçoamento/aquisição de competências. Para a empresa, a realização de um estágio profi ssional significa, além de vantagens fiscais, a oportunidade de testar o 
licenciado. Com efeito, muitas das empresas mencionam que, com a colocação de novos quadros, é necessário um pequeno período de aprendizagem para o licenciado e, durante esse mesmo tempo, a empresa pode testar as competências profissionais do quadro recém-admitido. Porém, é necessário também não esquecer que estes estágios podem confi gurar comportamentos propícios à inovação nas empresas e, por conseguinte, poten ciar a capacidade de (re)acção das empresas à actual envolvente dos mercados globalizados e competitivos.

Como nota dissonante, é de referir o pouco impacto que as Unidades de Inserção na Vida Activa (UNIVA) têm, sendo quase inexistentes para as empresas, já que a sua missão é justamente a de apoiar os actores envolvidos neste processo de transição.

Apesar da importância relativa junto dos licenciados, o papel das empresas privadas de recrutamento e selecção é manifestamente residual, se considerarmos as práticas dominantes nas empresas.

Portanto, enquanto os licenciados lançam mãos de todos os meios, não abdicando de avançarem com um conjunto de iniciativas individuais (e.g., dirigirem -se à empresas, colocarem anúncios de jornal, recorrerem aos conhecimentos pessoais) e institucionais, as empresas centram -se numa gestão individual dos meios de recrutamento, com particular destaque para a ênfase das qualidades pessoais dos trabalhadores, com implicações ao nível da individualização e subjectivação das relações de trabalho. Estes resultados apresentam-se consistentes com investigações internacionais (Teichler, 2007) quanto aos efeitos do background sociobiográfico dos jovens, em particular a sua origem social, ao traduzir implicitamente a capacidade de recorrer a redes familiares e de amizade, o que nos permite relativizar as relações, por vezes demasiado lineares, que se estabelecem entre o diploma e o emprego.

\subsection{Experiências de trabalho e representações sociais}

Os percursos profissionais podem compor-se de várias dimensões objectivas e subjectivas ao nível da relação emprego e trabalho. Como temos vindo a argumentar, o tipo de vínculo contratual constitui uma das dimensões objectivas relevantes para caracterizar os percursos profissionais. Contudo, as posições face à importância de um contrato de trabalho, às condições do exercício de uma actividade profissional e ao grau de satisfação face ao trabalho, entre outros aspectos, não se apresentam necessariamente coincidentes por parte dos jovens diplomados, variando em função da sua posição na trajectória biográ fica. Igualmente, variam em contextos de crise macroeconómica, instabilidade política e indefinição de políticas sociais. Para aprofundar algumas destas orientações sociovalorativas, socorremo -nos de excertos de entrevistas biográfi cas realizadas ao longo de três anos a jovens engenheiros (Marques, 2006) ${ }^{12}$.

Atente -se aos seguintes excertos de duas biografias analisadas em relação às suas condições contratuais:

(...) eu no início não tinha contrato nem recebia por recibos. Simplesmente ao fim do mês ele [patrão] passava -me o cheque e mais nada. (CIVIL: 2.2, sexo feminino) Neste momento gostaria de algo muito certo, algo seguro em termos de contrato e horários... (LIG: 2.1);

Julgo que é importante ter um emprego adequado à formação académica, para o futuro, em termos de desenvolvimento da carreira. (LIG: 2.2);

Digamos que ter um contrato de trabalho é sobretudo simbólico! (LIG: 2.3, sexo masculino) 
40 A precariedade em termos de salário, vínculo, definição de condições do exercício da actividade e do ajustamento às expectativas forjadas ao longo de uma formação académica surge aqui claramente vincada. Porém, não esgota as experiências e representações que se desenvolvem em torno dos quotidianos de trabalho.

Tenho pena de estar nos quadros! Não sinto necessidade nenhuma de estabilizar e, se calhar, até penso de maneira contrária. Estou a fazer dois anos na empresa e em Dezembro passado pensei mesmo em sair; entretanto alteraram as coisas e queria ver como é o arranque do projecto. Neste momento, estou a contar ficar mais um ano (...). Três anos já acho muito, muito tempo mesmo!"(LIG:4.3, sexo masculino)

Eu penso que o contrato neste momento, ao contrário do que era antigamente, não serve para nos defender, serve sim para defender a empresa. Para nós, quanto mais alargado e mais aberto estiver o contrato melhor, porque a mutação a nível de pessoas e a rotação dentro da própria empresa é alucinante. Eu tenho 'n' propostas para mudar, desde ir para o Sul, para o Norte do país. Posso mudar desde ir para a Austrália, em que há uma procura imensa de pessoal. (LIG: 3.3, sexo masculino)

Estes exemplos permitem -nos simultaneamente reforçar e relativizar a importância da estabilidade contratual. No entanto, antevê -se que esta dimensão não esgota a possibilidade de se convocar outras, que estão para além da questão do tipo de vínculo contratual. Trata -se, neste caso específico, de realçar a importância da empregabilidade e das modalidades de inserção que o diploma poderá conferir ao jovem. Por outras palavras, privilegia -se também uma abordagem assente na correspondência do diploma ao emprego, na concretização de uma carreira e na realização profissional, que podem não se fundamentar necessariamente na continuidade da relação laboral.

Para a sua análise, impõe -se ter em conta alguns factores condicionantes explicativos, uns mais previsíveis, nomeadamente a qualidade do estágio, a fileira de estudos em que se integra o diploma, o grau de enquadramento das funções, a possibilidade de desenvolvimento de qualificações e a projecção de uma carreira; outros mais latentes, como, por exemplo, os que derivam da persistência de certos modelos socioculturais que esquematizam papéis profi ssionais de género, de pertença social e profi ssional (Marques, 2004).

Outra condicionante das posições assumidas pelos jovens explica -se, em parte, pela percepção de uma fácil inserção profissional, baseada na ideia de deterem uma licenciatura que responde às necessidades das empresas. A percepção de se confrontarem com uma conjuntura caracterizada pela grande procura de quadros com este perfi 1 profissional aparece, assim, generalizada a estes jovens de formação nas áreas de engenharias e novas tecnologias.

Na verdade, há a referência explícita, ao longo das entrevistas realizadas, tanto à grande oferta de emprego, como à possibilidade de escolha daquele que melhor corresponde aos objectivos e estratégias profissionais dos jovens. Mesmo assim, atente -se na observação complementar que os entrevistados deixam escapar quanto à questão das menores condições ou menor adequação das funções a desempenhar em relação à formação académica recebida:

Nós, os engenheiros civis, não temos problemas para já com a oferta de trabalho.

(CIVIL: 6.2, sexo feminino)

(...) todas as empresas vão comprar sistemas de informação (...), penso que teremos um futuro promissor, desde que as pessoas mostrem valor e trabalho. (LIG: 3.1, sexo masculino) 
À noção vulgarmente associada de um "emprego para toda a vida", os jovens reflectem, em paralelo, a ideia inculcada de limitação temporal e de individualização da relação contratual (Sennett, 2001). Ou seja, a ideia de obterem um contrato de trabalho por alguns anos ou a de que não há hoje empregos permanentes transformam aquelas concepções. Contudo, tal como acontece com os seus homólogos europeus, a valorização do emprego passa também por este incluir oportunidades de carreira e de desenvolvimento da empregabilidade individual, para além da exclusiva modalidade de um emprego para toda a vida.

Este comportamento estratégico dos jovens, que permite jogar com as transformações rápidas dos conhecimentos e a necessária actualização profi ssional, num contexto em que prevalece um sentimento de insegurança no emprego e de receio do desemprego, contribui para reforçar aquela disposição de desenvolvimento pessoal:

Em princípio uma pessoa vai ganhar menos dinheiro, começa numa empresa mais pequena e depois vai progredindo para empresas maiores. (CIVIL: 3.1, sexo masculino)

Aprender e ganhar experiência profissional (...). (CIVIL: 4.1, sexo masculino)

A meu ver não interessa só ter um trabalho. Se uma pessoa não está bem numa empresa, se não está a corresponder às expectativas (...) se não puder aprender, só estou a perder tempo... (CIVIL: 6.2, sexo feminino)

Sublinhe -se, então, que a referida facilidade de inserção profissional se tem feito acompanhar de um agravamento de algumas condições de exercício da actividade profi ssional, nomeadamente no que se refere aos horários de trabalho. Mesmo quando detêm mais autonomia na realização do seu trabalho, os constrangimentos temporais e de resultados fazem -se sentir de forma signifi cativa:

Estou numa empresa que não paga isenção de horário e estou a trabalhar cerca de 11 horas por dia (...) neste momento estou completamente autónomo a trabalhar. Tenho um objectivo e para o atingir sou eu que trato de todo o processo. (LIG: 3.2, sexo masculino)

Era feito quase semanalmente um plano de trabalho pelo meu chefe que me era entregue. Ele próprio me dizia agora: desde que me apresente os resultados na data prevista o horário é por sua conta. ( LIG: 6.2, sexo feminino)

Está bem patente nestas passagens o quanto a intensidade da carga laboral limita as possibilidades de outras vivências. A intensificação excessiva dos ritmos de trabalho e dos prazos a cumprir tende a impossibilitar a vivência de outras temporalidades e experiências além da do contexto de trabalho. Nesta sequência, a possibilidade de se gerarem tensões entre os diferentes e vários espaços e tempos sociais, sobretudo familiar e privado, e a tendência para aumentarem problemas relacionados com o stress e a fadiga psicológica podem contribuir para um sentimento de empobrecimento da vida pessoal:

Eu não tinha lá [em Lisboa] família; tinha poucos amigos e então era quase casa trabalho. Não tinha tempo para mim. (LIG: 5.2, sexo feminino)

Eu não faço absolutamente nada (...) É casa -trabalho. Gostava de ter um emprego que me permitisse ter uma vida também. (LIG: 6.2, sexo feminino)

Note -se ainda que, mesmo em situações de inserção profi ssional pautadas pela relativa facilidade de obtenção do emprego, a correspondência deste com a formação académica recebida pode não se verifi car. Atente -se à biografi a de uma jovem licenciada em Informática de Gestão cuja primeira experiência de trabalho efectivo foi a de recepcionista de um hotel que só mais tarde (passados três meses), conseguiu ser colocada numa escola secundária em Lisboa. 
No princípio as coisas foram muito difíceis, depois de tentar inclusive empregos que não tinham nada a ver com a minha profissão, por exemplo, de recepcionista de hotel (...) entretanto saíram os resultados do concurso ao ensino. Peguei nas malas e parti para Lisboa. (LIG: 1.3, sexo feminino)

Neste sentido, a referência a dificuldades de inserção permite -nos realçar,

justamente, expectativas menos optimistas por parte das jovens, comparativamente com os seus colegas de sexo oposto:

É esquisito porque nós, as engenheiras civis, temos a certeza de que não vamos para obras. (CIVIL: 2 - Fevereiro/99, sexo feminino);

Ganhar experiência para me tratarem como engenheira civil! (CIVIL: 2.2, sexo feminino)

Já ouvi dizer que as empresas dão preferência aos homens para direcção de obras (...). (CIVIL: 6 - Fevereiro/99, sexo feminino);

Se não servir para obter conhecimentos [emprego] para um dia mais tarde ter uma empresa minha, como eu quero, só estou a perder tempo. Prefi ro estar numa empresa onde esteja a aprender alguma coisa. (CIVIL: 6.2, sexo feminino)

\section{A eficácia das práticas de socialização vigentes contribui para a recorrência}

de uma certa argumentação baseada na suposta passividade e conformismo das jovens do sexo feminino e consequente naturalização dos seus gostos, tendências, vocações, projectos e desejos. Eles e elas apoiam -se nessa argumentação e legitimam as (di)visões dos papéis sociais:

Muitas vezes as minhas colegas entram para uma área que não é delas e depois deixam -se acomodar. (LIG: 3 - Fevereiro/00, sexo masculino)

O homem esteve sempre fora de casa o dia todo (...). (LIG: 4.3, sexo masculino)

Os empregadores têm mais confiança nos rapazes do que em nós, mulheres. (...) Perguntavam se eu tinha disponibilidade para viajar, ficar até mais tarde... (LIG: 6.1, sexo feminino)

Muitas vezes, elas têm mais aptidão para gabinetes (...) se calhar porque uma pessoa tem aquela noção de que, nós homens, chegamos e conseguimos pôr o empregado na linha e fazer aquilo que queremos (...). (CIVIL: 5.2, sexo masculino)

A nível da sociedade nota -se uma grande diferença de papéis masculinos e femininos (...). Parece que continua a haver aquele culto de que o homem não se preocupa com certas actividades e a mulher ainda não acedeu a certas áreas. (CIVIL: 4.3, sexo masculino)

Porém, esta diferenciação de papéis sociais e profissionais com base no género tende a ser acompanhada por desiguais condições remuneratórias e de carreira. Não pretendendo aqui apresentar os resultados obtidos pelo inquérito, podemos mesmo assim referir que se observou uma associação consistente de melhores salários e posições organizacionais hierarquicamente superiores nos homens por comparação com as suas colegas. Nesse sentido, são signifi cativos, sobretudo, os testemunhos das jovens entrevistadas:

Quem trabalha na direcção de obras ganha muito mais. Não sei porquê! (...) Nós, na área em que estamos, quem define os salários é o patrão, normalmente, e tanto pode aumentar a mesma percentagem que na função pública, como pode aumentar menos ou até nada. Podemos estar a ganhar sempre o mesmo. (CIVIL: 6.3, sexo feminino)

A mim pagavam -se 450 euros a recibos verdes, claro. (LIG: 1.2, sexo feminino)

Por fim, importa considerar as relações ideológicas e simbólicas estabelecidas com o trabalho e os factores de satisfação profissional, que perpassam e, consequentemente, completam aquelas dimensões objectivadas no emprego, no diploma, na profissão, na carreira, na vida privada, entre outros aspectos. Por exemplo, o valor do salário e das 
relações instrumentais de um emprego na função pública está patente nesta jovem licenciada em Informática de Gestão:

Para mim, o trabalho é para ganhar dinheiro. (...) Se a gente concorrer para uma empresa, o salário será um pouco melhor; mas, no ensino, existem certas regalias que não existem nesse caso, tipo, terem férias, ter assistência médica... (LIG: 1.3, sexo feminino)

Também é importante separar e manter as fronteiras entre o tempo de trabalho e a vida privada:

Nunca prevejo ficar completamente absorvido pelo trabalho. (...). Acho que o trabalho deve ser considerado um meio! Não sei se vou alterar a minha opinião depois, mas agora é assim que eu penso (...) Independentemente do ordenado, acho mais importante ter fins-de-semana e ter um pouquinho da tarde...( LIG: 4.2, sexo masculino)

57 Mas o valor do trabalho como fonte de realização profissional e pessoal,

58 em particular nos jovens em início de uma actividade profissional, está presente nas seguintes passagens:

(...) Defendo que é realmente muito importante no sentido de carreira, do gosto pelo que se faz, construir qualquer coisa, aí sim, agrada -me mais essa ideia (...). Um bom trabalho seria mesmo aquele que nos aliciasse cada dia, saber que tinha ali uma coisa a vencer... (CIVIL: 4.1, sexo masculino)

Ter um emprego que eu realmente sentisse que estava a fazer aquilo que gostava e realizar-me a fazer aquele tipo de trabalho. Acho que era fundamental trabalhar com uma equipa de trabalho que se dê bem a trabalhar e que saiba trabalhar em conjunto (...). (CIVIL: 3.3, sexo masculino)

Parece razoável admitir que o trabalho e a satisfação profi ssional não vão deixar de constituir referências importantes de valores sedimentados nos jovens nas próximas décadas. Também é certo que, além destas, outras se foram impondo em complementaridade com o trabalho. De modo genérico, trata-se de referências reportáveis a certos padrões de consumo, de estilos de vida, de sociabilidade e tipos de lazer que se foram generalizando nas várias faixas etárias deste segmento juvenil. Ao mesmo tempo, a extensão da escolarização dos jovens e a elevação das aspirações em contexto escolar explicam parte dos movimentos de rejeição destes e dos jovens em geral em relação a certos empregos que apresentam condições organizacionais e produtivas taylorizadas ou que contribuem para a "anulação" dos saberes transportados para os contextos de trabalho.

60 Mas admitindo, dizíamos, que o trabalho e a satisfação profi ssional permaneçam como um dos eixos importantes de estruturação social, tal não impede que se sobreponham tendências de natureza diferente face ao contexto actual, caracterizado por fenómenos assentes nas dificuldades de acesso ao primeiro emprego, nas elevadas taxas de desemprego e na precariedade das condições de exercício profi ssional. Aceita -se, igualmente, que a difusão dos efeitos desses fenómenos oscile em função de características como o sexo, a idade, a classe social de origem, o nível de formação, a origem geográfi ca, entre outros. Distante das tendências homogeneizantes ou lineares, as dinâmicas sociais de transformação referentes ao ethos do trabalho evidenciam exigências de realização profi ssional e pessoal no trabalho por parte dos jovens "pressionados" em conciliá -las num contexto de crescente vulnerabilidade das relações de emprego. 


\section{Ressimbolização e processos de transformação do espaço social de trabalho: pistas em aberto...}

61 Se durante os "Trinta Anos Gloriosos" a questão social e as lutas operárias se centraram na transformação e construção de um direito do trabalho e de um modelo social europeu - o Estado Providência é expressão disso mesmo -, com a globalização e a reconversão tecnológica, a força do trabalho parece não conseguir continuar aquele projecto de emancipação e humanização a que se deu início após a II Guerra Mundial. Bem pelo contrário, o trabalho, no seu conteúdo e significado social, encontra -se metamorfoseado sob um registo e discurso neoliberal (Kovács, 2006b, 2002), operando -se uma reconversão ideológica em expansão na Europa e no mundo.

Ora, a dinâmica da actual fase do capitalismo tende a desmontar este edifício do Welfare State para se reduzirem os "gastos extralaborais" - embora, em Portugal este ainda se encontre a cumprir, de modo precário, alguns dos requisitos de solidariedade como, por exemplo, o rendimento mínimo - ao mesmo tempo que abre as portas à flexibilização das relações de emprego. Como se sabe, para facilitar este objectivo, a ideologia do "Estado mínimo" permite legitimar iniciativas de privatização de empresas públicas do sector produtivo e de serviços públicos de educação, saúde ou segurança social. A lógica de cariz quantitativo e produtivista impõe -se como forma de racionalização dos custos, sustentada na crença de que os modelos de gestão seguidos pelas empresas privadas se apresentam, por definição axiomática, automaticamente mais efi cientes e competitivos do que os das empresas públicas. Face a esta tendência, também as empresas públicas têm sido alvo de difusão, sobretudo a partir dos fi nais dos anos oitenta do século XX, de práticas gestionárias oriundas do modelo privado, fi cando a ser conhecidas por New Public Managen $t^{13}$. Esta nova abordagem às políticas públicas resulta quer da atribuição de critérios privados na gestão de organizações públicas (e.g., atribuição de funções de gestão a pro-fi ssionais; definição de padrões explícitos de desempenho; adopção de formas de medida desse desempenho baseadas na análise dos resultados alcançados; racionalização dos custos; maior proximidade das entidades responsáveis pela oferta de serviços ao utente que os procura), quer da promoção de uma maior competição, através da contratação externa de serviços (e.g. outsourcing) e da instituição de "quasi -mercados", assim como da aposta no exercício do direito de escolha por parte dos clientes/utentes como princípio basilar do funcionamento dos sistemas públicos de oferta de serviços. $\mathrm{Na}$ prática, este movimento tem como objectivo colocar no mercado "livre" produtos e serviços que, postos nas mãos do capital globalizado, deixam de estar sob a alçada do Estado, mas aos quais quase só podem aceder os que possuem os recursos económicos necessários ${ }^{14}$.

Assim, com base no que temos vindo a argumentar, fruto da progressiva regressão do Estado, visível pela privatização de vários serviços, a par do acréscimo de competitividade nas actuais economias globalizadas, importa referir os seguintes processos de ressimbolização do espaço social de trabalho: $i$ ) assumpção da "cultura de risco" e da incerteza na Sociedade do Conhecimento, a par do compromisso e confiança exigidas aos actores sociais (Sennett, 2001); ii) lógicas de intensificação e racionalização subtis dos modelos de organização do trabalho: contratualização e individualização das relações de trabalho; iii) não linearidade e homogeneidade dos processos de profissionalização: exigências de tecnicidade e disposições comportamentais adequadas; iv) dinâmica da 
reversibilidade e reconversão de percursos formativos: centragem na Aprendizagem ao Longo da Vida e na mobilidade transversal.

Estes processos concorrem para uma crescente "dualização social" e fragmentação das relações de trabalho, com incluídos e excluídos, estáveis e precários, empregados e desempregados, activos e inactivos, jovens e idosos, entre outros. A quebra de solidariedade entre estes diferentes grupos, que pode exprimir, em simultâneo, vários daqueles processos de dualização, contribui para o acréscimo de desigualdades sociais e para a "crise" do Estado Social. As transformações estruturais na natureza do capital e na produção que caracterizam esta nova fase de desenvolvimento do capitalismo parecem inaugurar uma reconversão ideológica para legitimar o modelo actual de mundialização do mercado de capitais, de tecnologia e produtos e, por último, da força de trabalho. Tal reconversão ideológica assenta no estilhaçamento progressivo, de forma objectiva e subtil, das conquistas sociais dos trabalhadores nas últimas décadas. De forma objectiva, trata -se das alterações no corpus legal de direitos reconhecidos em relação ao trabalho e às obrigações do Estado face aos trabalhadores. De forma subtil, trata -se da destruição de culturas de trabalho no sentido lato que os diversos colectivos modelaram, como resultado das suas experiências em processo de trabalhos específicos com base em relações concre tas de produção.

\section{BIBLIOGRAPHY}

ALMEIDA, Maria dos A. (2007), “A medição do emprego e desemprego: perspectivas conceptuais”, Sociedade e Trabalho, 31, $33-40$.

BAUMAN, Zygmunt (2000), Liquid Modernity, Cambridge: Polity Press.

BECK, Ulrich (2000), Brave New World of Labour. Cambridge: Polity Press.

BOLTANSKI, Luc \& CHIAPELLO, Ève (1999), Le Nouvel esprit du capitalisme. Paris: Gallimard.

BOURDIEU, Pierre (1989), o Poder Simbólico, Lisboa: DIFEL.

BOURDIEU, Pierre (1997), Razões Práticas - Sobre a teoria da acção, Oeiras: Celta Editora.

BOURDIEU, Pierre (1998), “La precarité est aujourd'hui partout” in P. Bourdieu, Contrefeux, Paris: Liber.

BOYER, Robert (coord.) (1986), La Flexibilité du travail en Europe, Paris: Éditions La Découverte. BOYER, Robert \& SAILLARD, Yves (orgs.) (1995), Théorie de la régulation - L'État des savoirs, Paris: Éditions La Découverte.

CASTEL, Robert (1991), “De l'indigence à l'exclusion, la désaffiliation, précarité du travail et vul nérabilité relationnelle”, in J. DONZELOT (org.), Face à l'exclusion, Paris: Esprit.

CASTEL, Robert (1995), Les Métamorphoses de la question sociale. Une chronique du salariat, Paris: Fayard.

CASTELLS, Manuel (1996), "The Rise of Network Society. The Information Age" in Economy, Society and Culture, Vol. 1, Britain: Blackwell Publishers. 
CASTILLO, Juan J. (1998), "Em busca do trabalho perdido (e de uma sociologia capaz de o encon trar...)”, in I. KOVÁCS \& J. CASTILLO, Novos Modelos de Produção: Trabalho e pessoas, Oeiras: Celta Editora.

CASTILLO, Juan J. (ed.) (1999), Trabajo del Futuro, Madrid: Editorial Complutense.

CÉLESTIN, J. -B. (2002), A Qualidade de Emprego, Lisboa: Direcção -Geral do Emprego e Formação Profi ssional (DGEFP).

CENTENO, L. Gomes (coord.) (2003), Avaliação do Impacto da Estratégia Europeia para o Emprego: Políticas activas para a empregabilidade, Lisboa: DEPP/MSST.

DUBAR, C. (2000), La Crise des identités. L'interprétation d'une mutation, col. Le lien social, Paris: PUF. DUBAR, C. (1991), La Socialisation. Construction des identités sociales et professionnelles, Paris: Armand Colin.

EUROSTAT (2007), European Employment Observatory (EEO), European Employment Observatory (EEO) (URL: http://www.eu -employment -observatory.net/index.aspx).

FREIRE, João (2001), “As atitudes sociais dos portugueses perante o trabalho", in AA.VV., o Futuro do Trabalho - Novas relações e competências. Oeiras: Celta Edição em CD -ROM.

FREIRE, João (1997), Variações sobre o Tema Trabalho. Porto: Afrontamento.

GAMST, Frederick C. (ed.) (1995), Meanings of Work. Considerations for the Twenty -First Century, Nova Iorque: State University of New York Press.

GAZIER, Bernard (1990), “L'employabilité: brève radiographie d'un concept en mutation", Sociologie du travail, n. $\frac{0}{4}, 575$-584.

GAZIER, Bernard (ed.) (1998), Employability - concepts and pratiques, Berlin: European Employment Observatory.

GIDDENS, Anthony (1992), As Consequências da Modernidade. Oeiras: Celta Editora.

GIDDENS, Anthony (1994), Modernidade e Identidade Pessoal. Oeiras: Celta Editora.

GIDDENS, Anthony (1999), The Runaway World. How Globalisation is Reshaping Our Lives, Londres: Profi le Books.

GOLLAC, M.; VOLKOFF, S. (1996), "Citius, altius, forties: l'intensification du travail”, in Actes de la Recherche en Sciences Sociales, n. ${ }^{\circ}$ 114, pp. 54 -67.

GOUDSWAARD, A. NANTEUIL, M. (2000), Flexibility and Working Conditions. A Qualitative and Comparative Study in Seven EU Member States. A Summary, Bruxelas: European Foundation for the Improvement of Living and Working Conditions.

HESPANHA, Pedro (2002), "Individualização, fragmentação e risco social nas sociedades globali zadas", in Revista Crítica de Ciências Sociais, n. 63, pp: 21 -31.

HESPANHA, Pedro \& CARAPINHEIRO, Graça (orgs.) (2002), Risco Social e Incerteza. Pode o Estado Social recuar mais?, Porto: Afrontamento.

KOVÁCS, I. (2006a), "Formas flexíveis de emprego em Portugal: riscos e oportunidades", Sociedade e Trabalho, 28, 17 -34.

KOVÁCS, I. (2006b), “As metamorfoses do trabalho e do emprego: alternativas para a crise do desemprego", in Oliveira, Isabel e Murteira, Mário (coords.), o Desemprego: Um desafi o à coesão social e à cidadania, Comissão Nacional Justiça e Paz, Abrigada: Editora Cidade Nova, 47 -77. 
KOVÁCS, I. (2002), As Metamorfoses do Emprego: Ilusões e problemas da sociedade de informação, Oeiras, Celta Editora.

KOVÁCS I. \& CASTILLO, J. (1998), Novos Modelos de Produção: Trabalho e pessoas, Oeiras, Celta Editora.

MARQUES, Ana P. (2009), Trajectórias Quebradas. A vivência do desemprego, Porto: Profedições/ Centro de Investigação em Ciências Sociais da Universidade do Minho.

MARQUES, Ana P. (2007), MeIntegra - Mercados e estratégias de inserção profi ssional. Licenciados versus empresas da Região Norte. Relatório final, Colecção DS/CICS. Universidade do Minho. URL:http://hdl.handle.net/1822/8633.

MARQUES, Ana P. (2006), Entre o Diploma e o Emprego: A inserção profissional dos jovens engenheiros, Porto: Afrontamento.

MARQUES, A. P. (2005), “Mercados profissionais e (di)visões identitárias entre jovens engenhei ros", Sociologia, n.ำ14, 165 -194.

MARQUES, Ana P. (2004), "Género na precariedade: tempos de trabalho em início de uma car reira”, in E. Figueira e L. Rainha (coords.) Qualificação e Género: O papel das competências-chave, Lisboa: Programa POEFDS/ IEFP. 123 -138.

MARQUES, Ana P. (2001), "Dinâmicas da relação entre trabalho e emprego: o fetiche da 'empre gabilidade permanente", Cadernos do Noroeste, Série Sociologia, Vol. 16 (1-2).

MARQUES, A. P. e DUARTE, A. (2003), "O estatuto da precariedade: notas sobre os percursos profissionais de jovens diplomados", in Inovação e Conhecimentos, Actas do X Encontro de SIOT, Lisboa: APSIOT, CD -Rom.

MARQUES, Ana P. SILVA, Manuel C. \& VEIGA, Carlos V. (2006), Assimetrias de Género e Classe. 0 caso das empresas de Barcelos. Barcelos: Kerigma.

MCQUAID, R. \& LINDSAY, C. (2005), The Concept of Employability. Urban Studies, 42. 2. 197-219.

MAUGER, Gerard (2001), “Les politiques d'insertion. Une contribution paradoxale à la déstabili sation du marché du travail”, in Actes de la recherche en Sciences Sociales, n.ำ 136 -137.

MEDA, Dominique (1995), Le Travail. Une valeur en voie de disparition. Paris: Aubier.

MORENO, Isidoro (1999), “Globalización, ideologías sobre el trabajo y culturas del trabajo”, Areas, n. ${ }^{\circ} 19,17-34$.

NICOLE -DRANCOURT, C. (1992), L’idée de précarité revisitée, Travail et Emploi. n.ํ⒌ pp. 37 -70

PAUGAM, Serge (1997), La Disqualification sociale. Essai sur la nouvelle pauvreté, Paris: Puf.

PAUGAM, Serge (2000), Le salarié de la précarité, Paris: Ed. Puf.

PINTO, J. Madureira (1991), “Considerações sobre a produção social de identidade”, Revista Crítica de Ciências Sociais. n. ${ }^{\circ}$ 32, 217 -231.

PINTO, J. Madureira (2001), "Ciências e progresso: convicções de um sociólogo", Caderno de Ciências Sociais, n.ำ 21 -22, 33 - 69.

POITET, Françoise (2007), Emploi et Travail. Le grand écart. Paris: Armand Colin.

REBELO, Glória (2003), Emprego e Contratação Laboral em Portugal: Uma análise sócio-económica e jurídica, Lisboa: RH Editora.

RIFKIN, Jeremy (1997), la fi $n$ du travail, Paris : La Découverte/Poche. 
RHODES, R. A. W. (1996), “The New Governance: Governing Without Government”, Political Studies , 44. 4, $652-67$.

RODRIGUES, M. J. (1991), Competitividade e Recursos Humanos. Sistema de emprego - Dilemas de Portugal na construção europeia. Lisboa: Publicações D. Quixote.

SANTOS, Boaventura de S. (2001), "Os Processos de Globalização", in Boaventura de S. Santos (Org.), Globalização - Fatalidade ou Utopia?. Porto: Afrontamento.

SANTOS, (1998), Reinventar a Democracia, Fundação Mário Soares/ Gradiva.

SAINSAULIEU, Renauld (1977), L'identité au travail, Paris: Presses de la Fondation Nationale des Sciences Politiques.

SAINSAULIEU, Renauld (1987), Sociologie de L'Organisation et de L'Entreprise, Paris: Dalloz.

SCHNAPPER, Dominique (1998), Contra o Fim do Trabalho, Lisboa, Terramar.

SENNETT, Richard (2001), A Corrosão do Carácter: As Consequências Pessoais do Trabalho no Novo Capitalismo, Lisboa, Terramar.

TEICHLER, U. (2007), Careers of University Graduates. Views and Experiences in Comparative Perspectives, col. «Higher Education Dynamics, n.ำ17, London: Springer.

TERSSAC, Gilbert de (1998), Savoirs, compétences et travail. In J. -M. BARBIER (dir.). Savoirs théoriques et savoirs d'action, Paris: PUF. pp. $223-247$.

\section{NOTES}

1. Não iremos aprofundar a complexidade dos debates desenvolvidos em torno da temática da globalização, não só por questões de economia de texto, como, sobretudo, por não ser esse o nosso enfoque teórico privilegiado. Porém, tal não impede que não se assuma como pano de fundo a tese dominante, certamente mais consensualizada, de que o modo como a globalização faz sentir os seus efeitos na economia e na sociedade não se apresenta transparente, nem linear (Hespanha, 2002; Hespanha e Carapinheiro, 2002; Santos, 2001). Os processos associados à globalização apresentam -se contraditórios: por um lado, assiste-se à liberalização e "homogeneização" de certos mercados, como financeiros, tecnológicos e de mercadorias; por outro, observam -se estratégias de "fechamento" de mercados profissionais (Marques, 2006), de reafirmação de movimentos de cariz identitário e localizado, de criação de "novas" barreiras de circulação de pessoas, catalogando os movimentos migratórios de "invasões", entre outros aspectos.

2. A este propósito, veja -se o número do anuário de relações exteriores, JANUS 2008, “O que está a mudar no trabalho humano", co -editado desde 1996 pelo jornal PÚBLICO e pela Universidade Autónoma de Lisboa (www.janusonline.pt).

3. Falar-se -á de "culturas de trabalho" no sentido próximo do da "teoria da aprendizagem cultural" (Sainsaulieu, 1977, 1987) em que a integração dos actores na rede de relações quotidianas de trabalho e nas estruturas da organização resulta dos seus posicionamentos hierárquicos diversificados, saberes e competências técnicas mobilizadas (qualificações e categorias socioprofissionais) e formas de comunicação, negociação e confl ito intraorganizacional existentes.

4. O mesmo raciocínio mercantilista tem acompanhado o não reconhecimento das actividades que integram o "terceiro sector" ou a economia social, apesar do seu relevante valor de uso (pela proximidade, dignifi cação e integração de públicos sociais). 
5. Seguimos de perto a proposta de definição de culturas de trabalho e sua inserção numa matriz identitária de Moreno (1999). Tal justifi ca -se porque nos parece que a sua proposta conceptual se apresenta heurística e com elevado potencial de operacionalização em investigações concretas. Igualmente, porque partilhamos também dos referentes estruturantes das culturas de trabalho, a partir das confi gurações sócio -históricas concretas. Porém, reconhecemos, tal como outros autores (Sainsaulieu, 1977, 1987; Dubar, 1991, 2000), que, além das dimensões materiais e simbólico -ideológicas, importa atender às dimensões interactivas que se desenvolvem em contexto de e no trabalho.

6. Serão mobilizadas informações substantivas, em particular os resultados obtidos no âmbito da investigação de doutoramento e que se encontram publicados na obra Entre o Diploma e o Emprego. A inserção profissional de jovens engenheiros (2006) e, mais recentemente, os resultados do projecto MeIntegra. Mercados e Estratégias de Inserção Profissional de Jovens Licenciados, desenvolvido entre 2006 e 2007 (POEFDS) e cujo relatório fi nal se encontra disponível na URL: http://hdl.handle.net/1822/8633.

7. Para lá da polémica que está associada ao termo "precariedade" (Marques \& Duarte, 2003; Paugam, 2000; Nicole -Drancourt, 1992), interessa -nos explicitar a ideia central da descontinuidade previsível do vínculo laboral, no tempo e no espaço de trabalho, como um dos traços de caracterização dos actuais percursos de inserção dos jovens licenciados.

8. Por exemplo "emprego dissimulado" que, sem ser ilegal em si, não é declarado a uma ou mais autoridades administrativas que dele devem ter conhecimento e que, por esta via, se encontra subtraído à regulamentação e tributação ou a uma redução das prestações da Segurança Social.

9. Com efeito, $16,9 \%$ das mulheres encontram -se com uma actividade profissional a tempo parcial, contra apenas $8 \%$ do sexo masculino (Eurostat, 2007).

10. Optámos, neste estudo, por acompanhar jovens licenciados das seguintes fi leiras científi cas: Humanidades, Ciência Sociais, Tecnologias e Engenharias da Universidade do Minho. O desenho metodológico que sustenta esta pesquisa é complexo e vasto, o que nos permite obter um conjunto diversificado de dados que extravasam a sua utilização restrita neste artigo. Para este ponto específi co do artigo, iremos socorrer dos principais resultados obtidos das entrevistas estruturadas realizadas aos jovens diplomados que concluíram a sua licenciatura no ano lectivo 2004/05 (um total de 464 entrevistas num universo de 1161 casos).

11. Igualmente, esta maior vulnerabilidade é mais vincada junto dos jovens quadros do sexo feminino quando comparada com os seus colegas do sexo masculino (Marques, 2007).

12. Para uma análise mais completa dos modelos de transição para a vida adulta, cf. Marques (2006,Cap.5).

13. Esta nova abordagem das plíticas públicas congrga vários movimentos distintos, mas complementares,como, por exemplo, o gerencialismo (managerialism), a nova economia institucional (Rhodes, 1996) e a teoria da escolha pública (public choice). Estes movimentos têm em comum o facto de desenvolverem uma crítica feroz oas sistemas burocráticos tradicionais dominantes.

14. São várias as críticas dirigidas a este modelo de gestão privada e assente na contratualização de relações de trabalho. Uma delas é a de estar perante uma novo "One Best Way", já que os princípios de gestão por objectivos são definidos independentemente dos contextos e situações de aplicação; em seguida, o achatamento/ descentralização das estruturas profissionais são acompanhadas pelo controlo fi nanceiro e coordenação orçamental, o que induz à existência de desequilíbrios nos processos de tomada de decisão; em seguida, não há qualquer atenção por parte desta teoria à dimensão comportamental da intervenção dos profissionais e, por último, não se confere qualquer especificidade à "coisa pública", já que o cidadão/ utente é um cliente como qualquer outro cliente numa lógica de mercado. 


\section{ABSTRACTS}

Desde o seu início que a Sociologia se tem preocupado com a análise do "trabalho" e dos seus efeitos na configuração da sociedade moderna, em particular na moldagem de valores, atitudes e comportamentos dos actores sociais. A passagem de um "emprego para a vida" para uma "empregabilidade para a vida" suscita várias interrogações, tais como: Qual o lugar do trabalho no mundo instável em que hoje vivemos? Que impactos sociais se poderão esperar das actuais tendências de fl exibilidade, mobilidade e precariedade no emprego? O trabalho está a humanizar-se ou a desumanizar-se cada vez mais? Este contribui para gerar maiores desigualdades ou para as reduzir? Neste artigo pretende-se: $i$ ) identificar os traços normativos, sociocognitivos e simbólicos específi cos da crescente individualização das relações de trabalho que caracterizam o início de carreira profissional de jovens diplomados; ii) reflectir sobre os processos de ressimbolização do trabalho que definem os principais contornos das relações de e no trabalho no actual regime de acumulação fl exível. Neste contexto, argumentar-se -á que a profusão de estatutos sociais diferenciados, decorrente de imperativos económico -políticos, de recomposições técnico -organizacionais e de dispositivos públicos de apoio ao emprego e formação, contribui para a delimitação de grupos sociais que se concentram, cada vez mais, em blocos de "integrados", "precários" e "excluídos" do mercado de trabalho.

Since its onset, Sociology has been concerned with the analysis of "work" and its effects on the configuration of modern society, particularly regarding the shaping of the social actors' values, attitudes, and conducts. The passage from "life-long employment" to "life-long employability" raises queries such as: What is the place of work in the unstable world we currently live in? Which social impacts can one expect from the current trends towards the flexibility, mobility,and precariousness of employment? Is work becoming ever more humane or inhumane? Does it contribute to engender additional inequality or to decrease it? In this article, one intends: i) to identify the specific normative, social-cognitive, and symbolic features of the growing individualization of work relations, which characterize the beginning of the professional career of young graduates; ii) to reflect on the processes of re-symbolisation of work, which define the main contours of work and within work relations under the current regime of flexible accumulation. In this context, it will be argued that the plethora of differentiated social statuses - a result of economical-political imperatives, of technical organisational re-compositions and of public mechanisms aimed at supporting employment and training - contributes to the delimitation of social groups that gather more and more round clusters of people who are "integrated in", "precarious" in face of, or "excluded" from the labour market.

Depuis sa création, la Sociologie a été consacrée à l'analyse du «travail» et ses effets dans la formation de la société moderne, en particulier dans la définition des valeurs, les attitudes et les comportements des acteurs sociaux. Le passage d'un «emploi pour la vie » à une «employabilité pour la vie» soulève plusieurs questions telles que: Quelle est la place du travail dans le monde instable dans lequel nous vivons aujourd'hui? Quelles sont les impacts sociaux des tendances actuelles de la flexibilité, la mobilité et l'emploi précaire qui ont peut attendre? Le travail tende humaniser ou à déshumaniser de plus en plus? Cela permet de générer de plus grandes inégalités ou les réduire? Cet article vise à: i) identifier les traits normatifs, sociocognitives et symboliques 
spécifiques individualisation croissante des relations de travail qui a caractérisé le début de carrière des diplômés ; ii) une réfl exion sur les processus de re-symbolisation du travail qui définir les grandes lignes des relations et de travaille dans le régime actuel d'accumulation flexible. Dans ce contexte, on peut argumenter que la profusion de statuts sociaux différents, en raison d'impératifs économiques, politiques, techniques et organisationnelles des réarrangements et dispositifs publics pour soutenir l'emploi et de formation, contribue à la délimitation des groupes sociaux qui se concentrent, de plus en plus, dans des blocs de «intégrée», «précaire» et «exclus» du marché du travail.

INDEX

Keywords: work and employment, precariousness, labour segmentation Mots-clés: travail et emploi, précarité, segmentation du travail

Palavras-chave: trabalho e emprego, precariedade, segmentação laboral

\section{AUTHOR}

\section{ANA PAULA MARQUES}

Departamento de Sociologia da Universidade do Minho amarques@ics.uminho.pt 